International Journal of Engineering \& Technology, $7(3.2)(2018) 354-359$
International Journal of Engineering \& Technology
WPC
Website www.sciencepubco.com/index.php/IJET
Research paper

\title{
Experimental Study on the Multikeyed Joints of Concrete and Reinforced Concrete Elements
}

\author{
Oksana Dovzhenko $^{1 *}$, Volodymyr Pohribnyi ${ }^{2}$, Leonid Karabash ${ }^{3}$

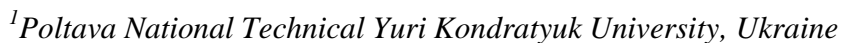 \\ ${ }^{2}$ Poltava National Technical Yuri Kondratyuk University, Ukraine \\ ${ }^{3}$ Poltava National Technical Yuri Kondratyuk University, Ukraine \\ *Corresponding Author E-Mail: O.O.Dovzhenko@Gmail.Com
}

\begin{abstract}
The connections ensure teamwork under the load of buildings and structures bearing elements. Joints distraction leads to a change in the structures support conditions and their design schemes. Keyed joints are the most effective under significant shear force action because they have high shear resistance. This makes it necessary to further improve their design solutions. In the article the experimental study results of multikeyed joints two series are presented. The joint models were tested in the department laboratory of reinforced concrete and stone structures and resistance of materials Poltava National Technical Yuri Kondratyuk University. The keyed profile (key's depth to height ratio and load application surface angle), reinforcement (quantity of reinforcement and its location character), seam width, keys number were varied in experiments. Heavy-weight concrete, expanded clay concrete and polypropylene fiber concrete were used for the samples manufacture. In experiments the influence of one of listed factors and their combinations for bearing capacity were studied. The concrete and reinforcement strains, distraction character, the failure load were studied. The influence degree analysis of the factors determining the strength was carried out. The design joints parameters that correspond to maximum strength were determined.
\end{abstract}

Keywords: Joint, Connection, Factors of influence, Strength.

\section{Introduction}

Load bearing elements joints are the important constituents of the structural system. Keyed joints have an increased shear resistance and they are effectively used in the construction industry.

Such joints are the most common variant of the vertical joints of wall panels. Precast concrete shear wall panels are used extensively in high rise construction. Their popularity is mainly due to the high quality achieved at the factory, as well as the high building construction speed.

Keyed connections are used in noncantilevered joints of beams with columns. If necessary keys are placed in joints of two-branch columns with foundations along the larger sides of branches crosssections.

In the cast-in-place and precast constructions there are keyed joints (dry contact joint).

Bridges with post-tensioned segmental box girders consists of "small" stressed precast elements. The behavior of such bridges at both serviceability and ultimate strength conditions is dependent on the behavior of the joints between the segments.

For the construction of space structures joints with concrete keys and connection bars are used.

The keyed joints wide use in different construction sectors necessitates their further study.

Numerous experimental and theoretical researches of multikeyed joints are known. The multikeyed joints with different profile configurations, the sizes of keys, reinforcement, the level of compression and the type of concrete were tested [1-5].

A series of experiments was carried out to study the shear capacity of the multiple keyed joints currently used in post-stressed horizontal connections for elevator shaft shear wall panels [6] Seven key connections were tested, which had 5 and 8 keys, including two different key configurations (slope angle $\psi$ of the bearing faces to the horizontal was $7^{\circ}$ and $23^{\circ}$, key's width to height ratio $l_{k} / h_{k}=0.35$ and 0.5 ). Two levels of compressive stresses, 2 and $4 \mathrm{MPa}$, were applied normal to the connection. The measured concrete compressive strength ranged between 30 and $50 \mathrm{MPa}$.

It is known that the average magnitude shear stress across the keyed joints decreases as the keys number increases. Numerical joint models with one, three, five and seven keys were developed [7], and a regression equation for determining shear capacity depending on the keys number and prestressing was presented. The proposed relationships are applicable for prestressing up to $3 \mathrm{MPa}$ and concrete compressive strength up to $50 \mathrm{MPa}$. It is further concluded that for higher prestressing the joint behavior is independent of the keys number.

Similar questions were considered in $[8-10]$. The most important feature of the developed finite element joint model is that it has been validated with experimental tests on concrete panels which were specifically designed to investigate the shear.

Paper [11] presents a new connection of precast reinforced concrete shear wall elements. The precast elements are connected by a narrow seam grouted with mortar and reinforced with overlapping U-shaped bar loops. Contrary to conventional shear connections, the planes of the U-shaped bar loops are here parallel to the plane of the wall elements. This makes it possible to eliminate the risk of reinforcing bars collision during assembly of the elements. The core of mortar inside each U-shaped bar loop is reinforced with a transverse double T-headed bar to ensure transfer of tension between the overlapping U-shaped bars. The 
joint geometry influence on failure was investigated experimentally. The program included preliminary exploration of 25 specimens. Preliminary 7 specimens were investigated. Specimens with the new design were compared with conventional design specimens with identical geometrical joint properties. The remaining 18 samples were divided into two series which differed in the geometry of the keys. The connections had 3 keys with trapezoidal configuration, key's width to height ratio was $l_{k} / h_{k}=$ $0.07-0.23$, compression strength of mortar was $30.6-42.7 \mathrm{MPa}$, U-shaped bar diameter was $8 \mathrm{~mm}$, U-shaped bar yield strength was $f_{y}=487 \mathrm{MPa}$. The key dimensions' significance has been addressed and the key height and depth influence on the failure mode has been outlined.

Higher quality joint can be obtained by replacing the U-shaped bars with high strength looped wire ropes. The wire ropes advantage is their flexibility (they have virtually no bending stiffness) which makes wall elements installation much easier. Loop ropes are usually pre-placed in so-called wire boxes, which are built into precast wall elements. Once the joint is grouted with mortar, the boxes will function as shear keys and the overlapping wire loops will function as transverse reinforcement that replaces the U-shaped bars. The results of studies of such 4 key joints are presented in [12-14].

Recently, the demand for record length, height and size of loadbearing structures predetermines the need to develop materials overcoming the limitations of the current high strength concrete. This led to the development of Ultra High Performance Concrete (UHPC) satisfying basic mechanical characteristics. Paper [15] presents the experimental study on the behavior of shear keys according to the curing time of UHPC in joint necessary for the construction of precast structures. In $[16,17]$ the results of studies of the ratio $l_{k} / h_{k}$, the support surface inclination angle and levels of compressive stresses on the load-bearing capacity of two-keyed joints are presented. In the experiments, the joints bearing capacity increase was recorded with the keys support surface inclination angle increase and the levels of compressive stresses.

\section{Experimental Program}

At PoltNTU during 1985 - 2017 years, system studies of keyed joints of concrete and reinforced concrete elements were carried out $[18,19]$. Seven series of the experimental samples have been made and tested. Description of the results obtained in the first 5 series is given in [20].

According to the received data parameters of both key and seam depend on strength of joints (fig. 1).

The samples code of the sixth and seventh series includes: the code first number is the number of keys in the joint; lettering; joint width $t_{j}$ (for 6 series); the ratio $l_{k} / h_{k}$; shape of the profile; concrete type; reinforcement ratio $\rho_{w}$; reinforcement location along the key's height.

The samples sixth series included three-keyed joints (19 samples) with the following variables: the supportting surface angle $\psi$, seam width $t_{j}$ and the reinforcement location character placement (fig. 2). The research has been carried out in order to determine the influence of these factors on the experimental sample strength. Ceramsite and polypropylene fibre concrete were used for joints filling.

The seventh series (6 samples) has been made for estimating the irregularity of the tangential stress distribution along the length of the jointing, as well as the influence of keys number and their reinforcement on the strength. This series included contact ceramsite concrete joints with one, three or five keys, and also with cross reinforcement and without it. The parameters of experimental samples are given in the table.

Both moment and momentless loading schemes have been implemented during the testing. Samples were made in two stages from concrete of two different classes. First, external parts of test samples from concrete of higher strength were made. Their lateral faces had a keyway profile. Later, the seam between them was concreted. Samples testing process is described in [21].

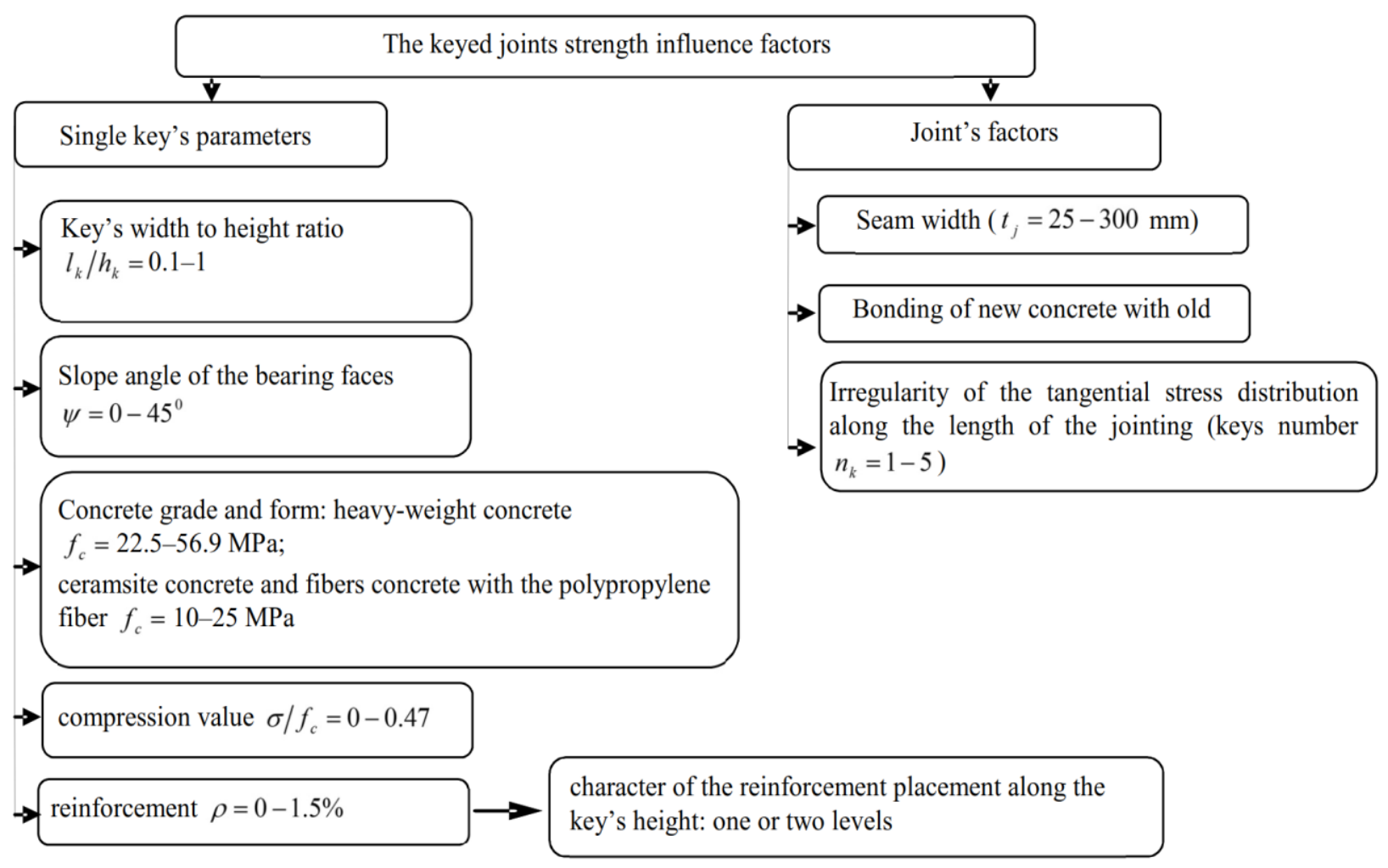

Fig.1: The strength influence factors of the concrete and reinforced concrete keyed joints. 


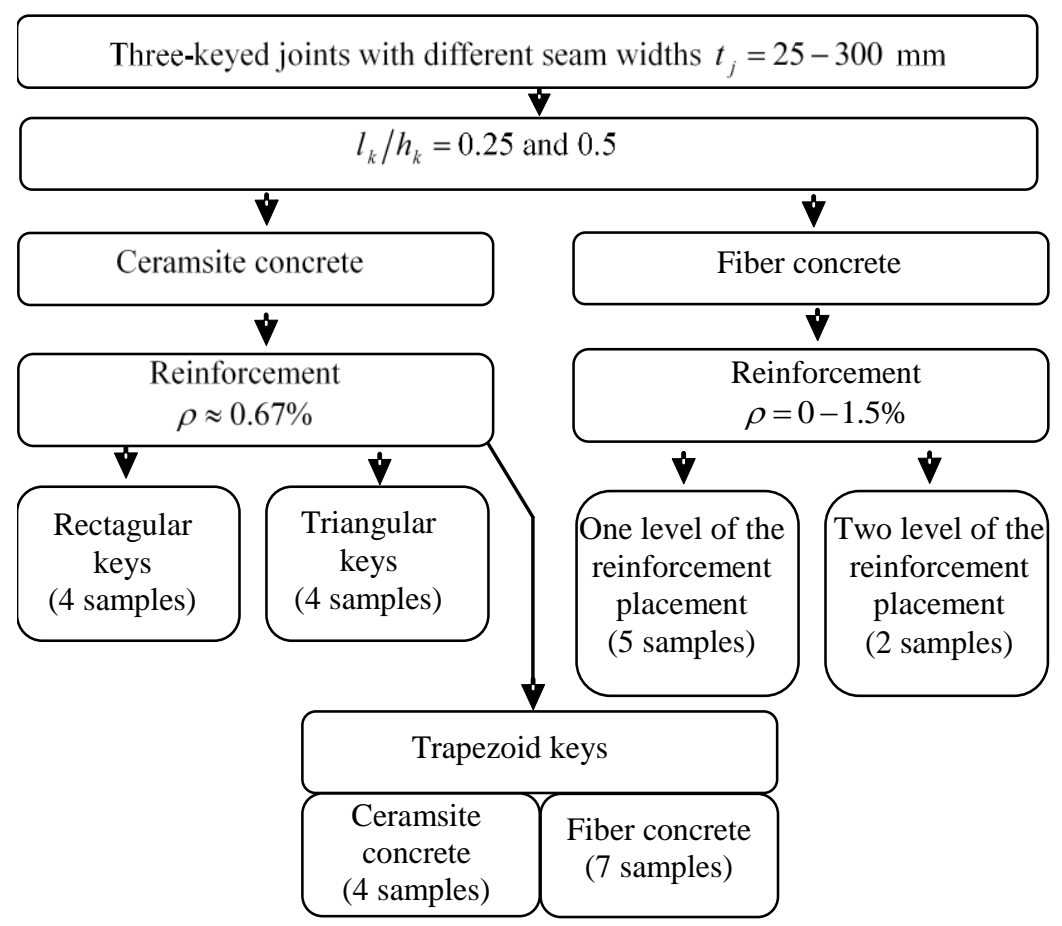

Fig. 2: The experiments program for samples of $6^{\text {th }}$ series

Table: Parameters of experimental samples of multikeyed joints

\begin{tabular}{|c|c|c|c|c|c|c|c|c|c|c|c|c|}
\hline \multirow{2}{*}{$\begin{array}{l}\text { № } \\
\text { se- } \\
\text { ries }\end{array}$} & \multirow[t]{2}{*}{ Samples code } & \multicolumn{3}{|c|}{$\begin{array}{c}\text { Keys geometric } \\
\text { parameters, } \\
\mathrm{mm}\end{array}$} & \multirow[t]{2}{*}{$\psi^{0}$} & \multicolumn{2}{|c|}{$\begin{array}{c}\text { Concrete strength } \\
\mathrm{MPa}\end{array}$} & \multicolumn{2}{|c|}{$\begin{array}{l}\text { Cross } \\
\text { reinforcement }\end{array}$} & \multirow{2}{*}{${ }^{t_{j}}$} & \multirow{2}{*}{$n_{k}$} & \multirow{2}{*}{$\begin{array}{l}V_{u}^{* *}, \\
\mathrm{kN}\end{array}$} \\
\hline & & $h_{k}$ & $b_{k}^{*}$ & $l_{k}$ & & $f_{c}$ & $f_{c t}$ & amount & $\begin{array}{l}f_{y w}, \\
\mathrm{MPa}\end{array}$ & & & \\
\hline 1 & 2 & 3 & 4 & 5 & 6 & 7 & 8 & 9 & 10 & 11 & 12 & 13 \\
\hline \multirow{17}{*}{6} & $3 \mathrm{KJW}-50-0.25-\mathrm{R}-\mathrm{C}-0.66-1$ & \multirow{17}{*}{100} & 153 & \multirow{7}{*}{25} & \multirow{3}{*}{0} & \multirow{7}{*}{12.9} & \multirow{7}{*}{1.6} & \multirow{7}{*}{$3 \times 2 \varnothing 8$} & \multirow{17}{*}{240} & 50 & \multirow{17}{*}{3} & 165 \\
\hline & $3 \mathrm{KJW}-150-0.25-\mathrm{R}-\mathrm{C}-0.66-1$ & & 152 & & & & & & & 150 & & 140 \\
\hline & 3KJW-200-0.25-R-C-0.60-1 & & 168 & & & & & & & 200 & & 125 \\
\hline & $3 \mathrm{KJW}-50-0.25-\mathrm{Tr}-\mathrm{C}-0.64-1$ & & 157 & & \multirow{4}{*}{17} & & & & & 50 & & 170 \\
\hline & 3KJW-100-0.25-Tr-C-0.63-1 & & 160 & & & & & & & 100 & & 170 \\
\hline & $3 \mathrm{KJW}-150-0.25-\mathrm{Tr}-\mathrm{C}-0.62-1$ & & 162 & & & & & & & 150 & & 160 \\
\hline & 3KJW-200-0.25-Tr-C-0.64-1 & & 158 & & & & & & & 200 & & 150 \\
\hline & $3 \mathrm{KJW}-50-0.5-\mathrm{T}-\mathrm{C}-0.64-1$ & & 157 & \multirow{10}{*}{25} & \multirow{3}{*}{0} & \multirow{3}{*}{10.4} & \multirow{3}{*}{1.2} & \multirow{3}{*}{$3 \times 2 \varnothing 8$} & & 50 & & 160 \\
\hline & 3KJW-150-0.5-T-C-0.67-1 & & 150 & & & & & & & 150 & & 130 \\
\hline & 3KJW-200-0.5-T-C-0.68-1 & & 148 & & & & & & & 200 & & 120 \\
\hline & 3KJW-100-0.25-Tr-F-0.75-2 & & 150 & & \multirow{7}{*}{17} & \multirow{7}{*}{9.7} & \multirow{7}{*}{1.36} & & & 100 & & 153 \\
\hline & $3 \mathrm{KJW}-150-0.25-\mathrm{Tr}-\mathrm{F}-0.69-2$ & & 163 & & & & & $3 \times 406$ & & 150 & & 142 \\
\hline & 3KJW-100-0.25-Tr-F-0.66-1 & & 153 & & & & & & & 100 & & 146 \\
\hline & 3KJW-150-0.25-Tr-F-0.64-1 & & 158 & & & & & $3 \times 208$ & & 150 & & 133 \\
\hline & $3 \mathrm{KJW}-25-0.25-\mathrm{Tr}-\mathrm{F}-1.48-1$ & & 152 & & & & & & & 25 & & 199 \\
\hline & $3 \mathrm{KJW}-150-0.25-\mathrm{Tr}-\mathrm{F}-1.49-1$ & & 151 & & & & & $3 \times 2 \varnothing 12$ & & 150 & & 176 \\
\hline & $3 \mathrm{KJW}-300-0.25-\mathrm{Tr}-\mathrm{F}-1.49-1$ & & 151 & & & & & & & 300 & & 163 \\
\hline & $1 \mathrm{KJ}-0.3-\mathrm{R}-\mathrm{C}$ & & & & & & & & & & 1 & 92 \\
\hline & $3 \mathrm{KJ}-0.3-\mathrm{R}-\mathrm{C}$ & & & & & & & - & - & & 3 & 212 \\
\hline & $5 \mathrm{KJ}-0.3-\mathrm{R}-\mathrm{C}$ & 00 & & & 0 & & & & & & 5 & 265 \\
\hline 1 & $1 \mathrm{KJ}-0.3-\mathrm{R}-\mathrm{C}-0.7-1$ & 90 & 150 & 30 & 0 & 22.5 & 1.8 & $2 \varnothing 8$ & & - & 1 & 137 \\
\hline & 3KJ-0.3-R-C-0.7-1 & & & & & & & $3 \times 2 \varnothing 8$ & 240 & & 3 & 305 \\
\hline
\end{tabular}

* - thickness of sample; $* *$ - the value of failure load

\section{Results Analysis and Discussion}

One of the possible failure schemes of three-keyed joints with $l_{k} / h_{k}=0.25$ and distance between keys that is equal to key's height $h_{k}$ (fig. 3) has been determined depending on the $t_{j}$ in the load level $(0.8-0.9) V_{u}$ :

- the first case was the shear of three keys by the joint's seam $t_{j}=25 \mathrm{~mm}$; the most downloaded key has been destroyed as the first (lower left or upper right one of the contact joint); 
- in the II case $\left(t_{j}=25,50,100,150 \mathrm{~mm}\right)$ the most downloaded key has been sheared as the first, and then the vertical crack along the height of the middle key and the inclined crack within the seam of the last key have been formed; the failure of two extreme keys with the appearance of the inclined crack within the limits of the middle one also has been observed;

- the III case can be characterized by the shear of the extreme key with the formation of the inclined cracks inside the joint within the other two keys $\left(t_{j}=150,200 \mathrm{~mm}\right)$;

- by joint's width $t_{j}=300 \mathrm{~mm}$ failure was along the inclined plane within the limits of all the joint (IV case); and keys themselves were not collapsed.

So the joint's width determines failure character and as a result significantly influences the ultimate load. In the conducted experiments the last one decreases to $20 \%$ with the increase of $t_{j}$ for trapezoidal profile.

While studying three-keyed joints with $\psi=0-45^{\circ}$ the statement has been approved that the triangular keys have the highest
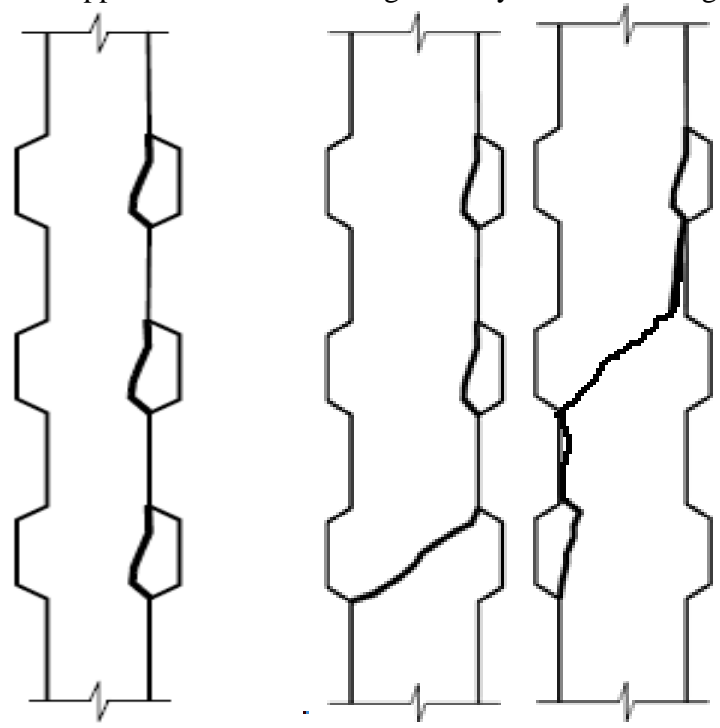

I case
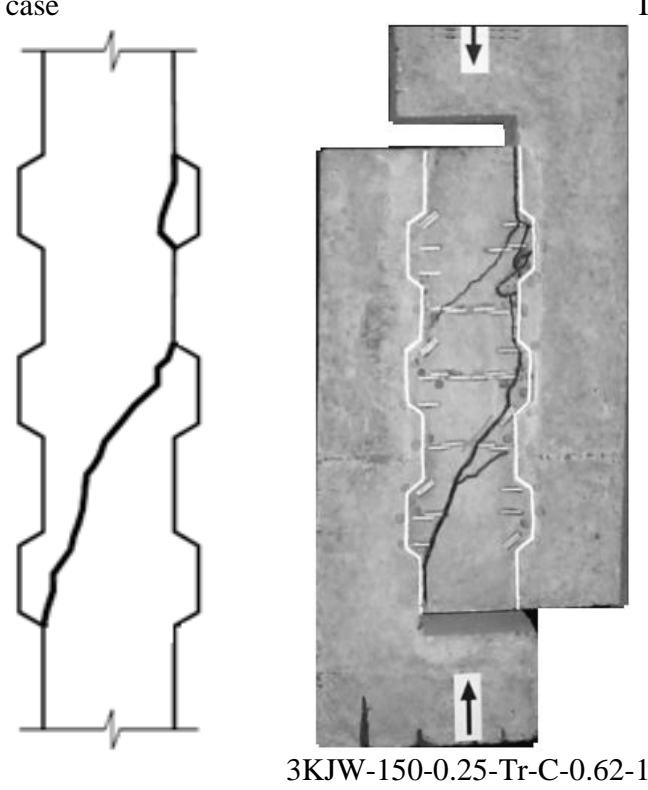

III case

Fig. 3: The failure character of the three-keyed joints made from fibre concrete with the trapezoidal keys.

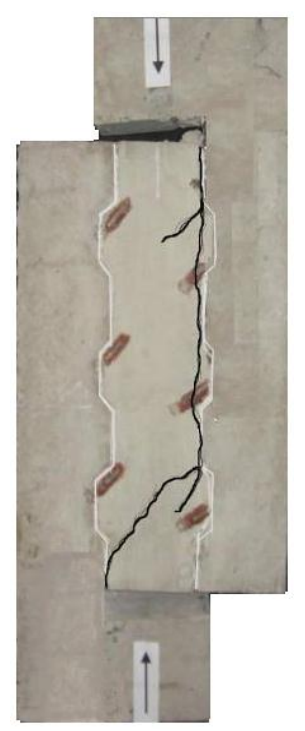

$3 \mathrm{KJW}-150-0.25-\mathrm{Tr}-\mathrm{F}-0.64-1$ II case
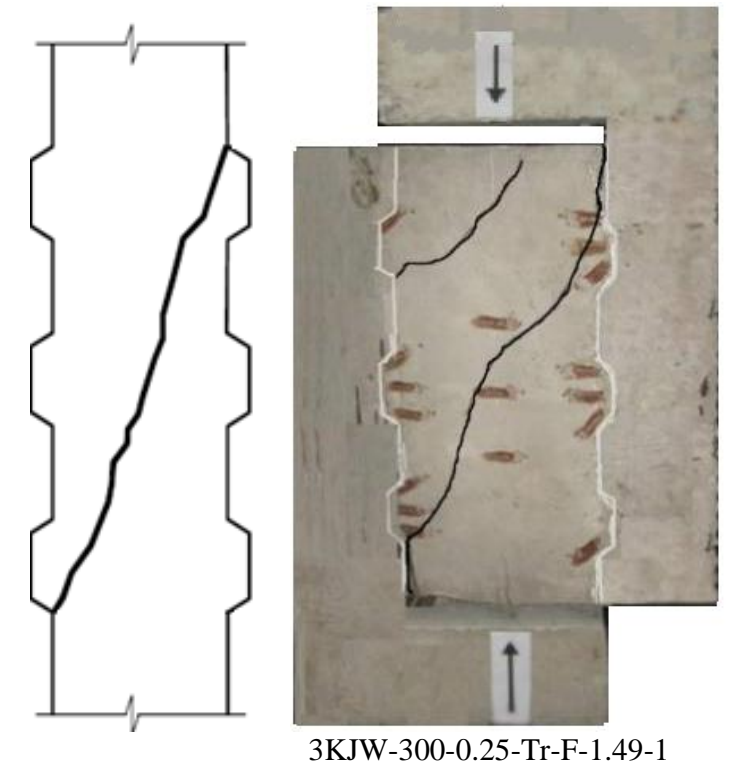

IV case

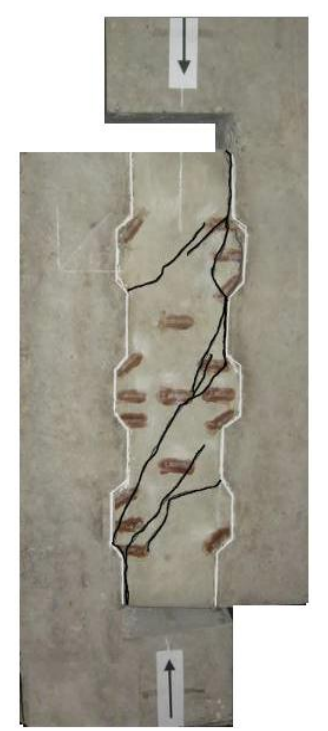

3KJW-150-0.25-Tr-F-1.49-1 strength (fig. 4). Similar results were obtained for joints with different keyed profile in $[22,23]$.

In the case of inclination of key's loaded surface, the shear dominates over tearing due to the concrete deformations transverse limitation. This limitation is caused by the presence of a horizontal force of the thrust, which arises in trapezoidal and triangular keys. In such joints, the reinforcement begins to perceive the load in the earlier stages of joint operation. The resultant load inclination changes the compressive stresses direction compared to the rectangular key.

Connections with the reinforcement along the height of the key have load bearing capacity slightly more $(10 \%)$ than similar samples with its location in the middle of the key.

The keys destruction surface under the shear has a curvilinear outline and includes zones of compression and tension. Tension prevails over compression. The tensile zone occupies up to $90 \%$ of the keys height. 


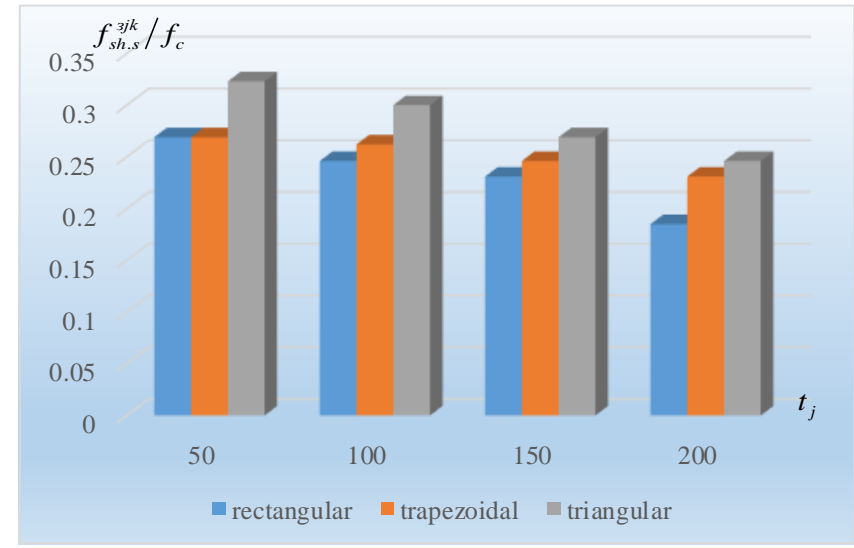

Fig. 4 The strength of three-keyed joints of ceramsite concrete $f_{\text {sh.s }}^{\text {sjk }}$ on the width of the seam $t_{j}$.

However, as the reinforcement factor increases, the size of the compressed zone increases.

Analysis of compressed zone concrete strain shows that its ultimate magnitude corresponds to strain at the top of the concrete mechanical state diagram, they increase with an increase in the reinforcement ratio and a two-level reinforcement placement.

Rods placed in the tensile area of the samples with the spacedapart reinforcement along the key's height had deformations $40 \%$ more than one-level reinforcement.

In joints with higher reinforcement ratio and two-level reinforcement there were maximum strain. Rods placed in the tensile area of the samples with the spaced-apart reinforcement along of the key's height had deformations $40 \%$ more than onelevel reinforcement

Rods located in the tensile zone (in incoming corners) at the twolevel placement are included in the work in the earlier stages of loading compared with the rods located in the middle. The usage of the fiber reinforced concrete as the material for keyed joints led to changes in the character of the cracking and samples failure. First cracks appeared at more high loading levels comparing to ceramsite concrete jointing. Also failure was more ductile and extended in time.

The strength of multikeyed joints increases nonlinearly with the increase of keys quantity $n_{k}$ (fig. 5).

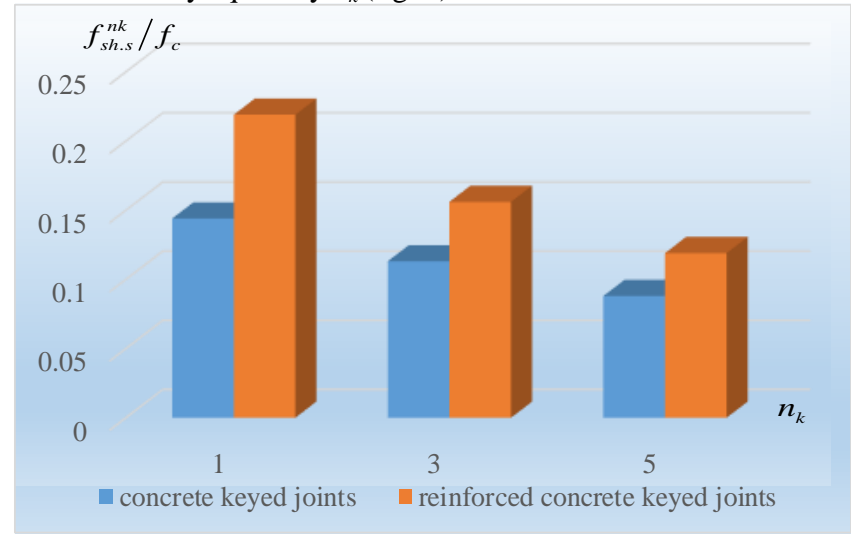

Fig.5: Keyed joints strength $f_{s h . s}^{n k}$ depending on the number of keys.

All samples from the seven series collapsed by the shear (fig. 6). At loading of $0.7 V_{u}$ in the most loaded bottom keys of three- and five-keyed samples cracks appeared near the shear plane. At the loading level of (0.8-0.9) $V_{u}$ the crack width reached $0.7 \mathrm{~mm}$ and also new cracks appeared in the middle and top keys.

Failure was followed with the displacement of the side members relative to the middle one. The reinforced joints collapsed under the bigger load comparing with the unreinforced ones.

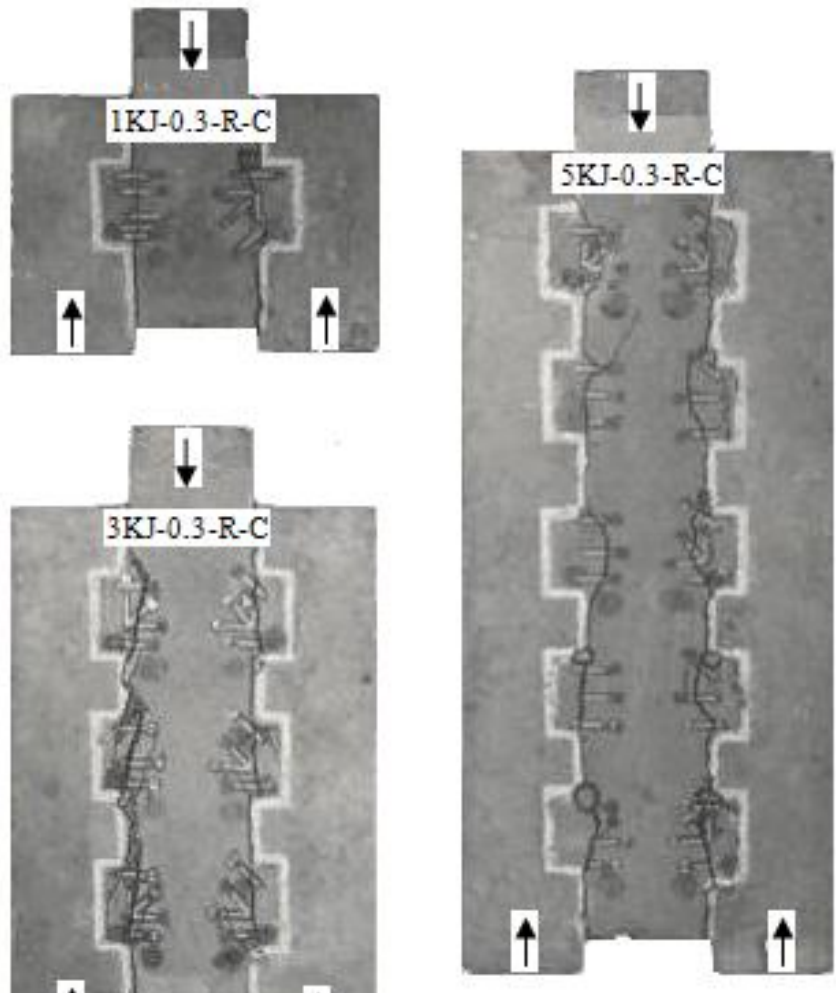

(a)
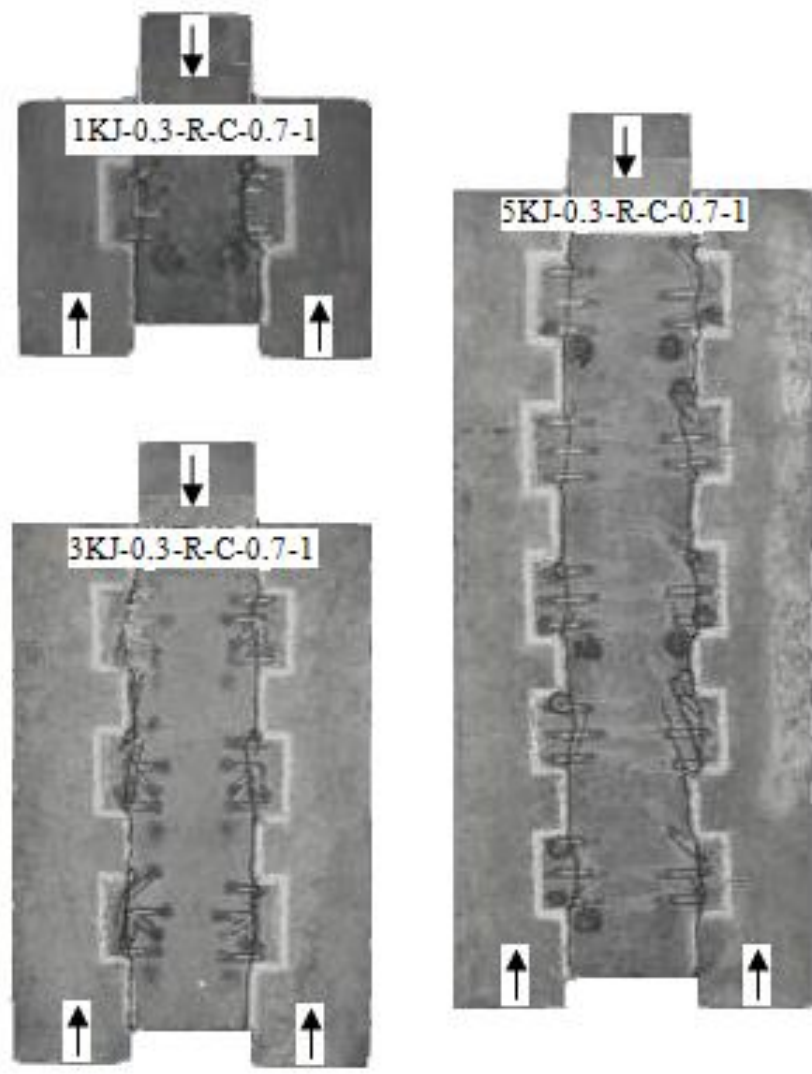

(b)

Fig. 6: The failure character of the samples with different number of keys: (a ) concrete keyed joints samples; (b) reinforced concrete keyed joints samples.

It happened when reinforcement stress in more tensioned keys reached the yield point. Irregularity of the concrete and reinforcement deformations has been noticed along the length of 
the multikeyed joins (fig. 7). It increases with the decrease of the seam's width.

The research allowed to establish qualitative and quantitative influence of separate factors on the joints strength and to receive new information about their combination.

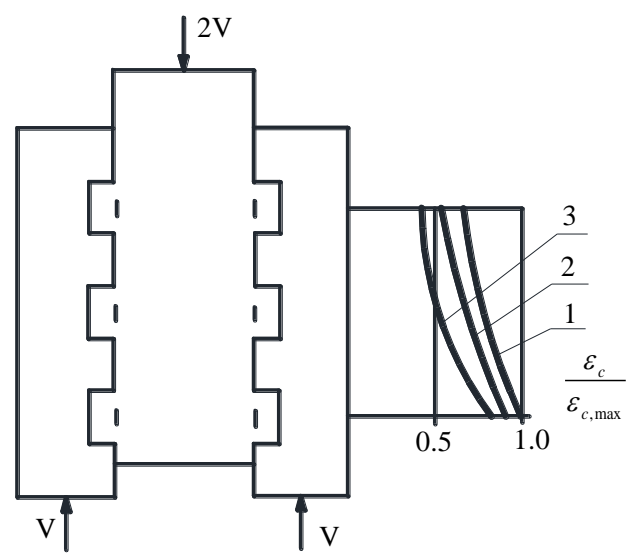

Fig. 7: Concrete strain distribution along the joint length in the sample $3 \mathrm{KJ}-0.3-\mathrm{R}-\mathrm{C}-0.7-1: 1-\mathrm{V} / \mathrm{V}_{\mathrm{u}}=1 ; 2-\mathrm{V} / \mathrm{V}_{\mathrm{u}}=0.87 ; 3-\mathrm{V} / \mathrm{V}_{\mathrm{u}}=0.79$.

\section{Conclusion}

The received data allow to make the following conclusions:

1. For three-keyed joints next variants are possible: shearing of the three keys, shearing of the two keys and seam failure in the limits of the third key, shearing of one of the keys and seam failure in the limits of other ones, failure over the seam.

2. With the increase of the seam's width its strength decreases.

3. The irregularity of key's work was noticed along the joint in the multikeyed joints. For example, the ultimate load of the fivekeyed joints only 3 times more than of the one-keyed. So dependency of the ultimate load on the number of keys is not linear. The actual number of keys with reduction factors must be given in design of multikeyed joints strength.

4. The reinforced concrete multikeyed joints strength with triangular keys is higher than strength of rectangular keys to $15 \%$ when the keys support surface is $45^{\circ}$.

5. In the experimental studies an increase of reinforced joints loadbearing capacity up to 2.5 times in comparison with concrete joins was established.

6. In addition to increasing of the strength by 1.1 times, the reinforcement displacement to the key incoming corners leads to an increase in the concrete plastic properties with an increase in the strain value by a factor of 1.5 .

7. Before the joint destruction, the strain of the concrete and reinforcement significantly increased. The yield of the reinforcement is fixed at the failure time at a reinforcement percentage of up to $1 \%$.

8. The joints crack resistance and strength is increased when using fiber-reinforced concrete on polypropylene fibers for the joint grouting. Also, the distraction nature changes to more plastic.

\section{References}

[1] Araujo DL, Debs MK (2005), Beam-slab connection in precast bridge decks with pockets filled out with high-performance concrete and shear key, IBRACON Structural Journal, Vol. 1, № 1, pp: 1-28.

[2] Qiang Han, Yu-Long Zhou, Zi-Lan Zhong, Xiu-Li Du (2017), Seismic Capacity Evaluation of Exterior Shear Keys of Highway Bridges, Journal of Bridge Engineering, Vol. 22, Issue 2, https://doi.org/10.1061/(ASCE)BE.1943-5592.0000978

[3] Zhan-Yu Bu, Wei-Ye Wu (2018), Inter shear transfer of unbonded prestressing precast segmental bridge column dry joints, Engineering Structures, Vol. 154, pp:52-65, https://doi.org/10.1016/j.engstruct.2017.10.048
[4] Xiangming Zhou, Neil Mickleborough, Zongjin (2005), Shear strength of joints in precast concrete segmental bridges, ACI Structural Journal, Vol. 102 (1), pp:3-11.

[5] Haibo Jiang, Li Chen, Zhongguo John Ma, (2005) Wenxian Feng Shear, Behavior of Dry Joints with Castellated Keys in Precast Concrete Segmental Bridges, Journal of Bridge Engineering, Vol. 20, Issue 2, https://doi.org/10.1061/(ASCE)BE.1943-5592.0000649

[6] Rizkalla SH, Serette RL, Heuvel JS, Attiogbe EK (1989), Multiple shear key connections for precast shear wall panels, PCI Journal, № $3-4$, pp:104-120.

[7] Alcalde M, Cifuentes H, Medina F (2013) Influencia del número de llaves en la resistencia a cortante de juntas secas postensadas [Influence of the number of keys on the shear strength of posttensioned dry joints], Materiales de Construcción, Vol. 63 (310), pp:297-307, https://doi.org/10.3989/mc.2013.07611

[8] Turmo J, Ramos G, Aparicio AC (2006), Resistencia de juntas secas conjugadas de puentes de dovelas prefabricadas de hormigón: propuesta para el Eurocódigo 2 [Shear strength of match cast dry joints of precast concrete segmental bridges: proposal for Eurocode 2], Mater. Construcc., Vol. 56 (282), pp:45-52, https://doi.org/10.3989/mc.2006.v56.i282.26

[9] Turmo J, Ramos G, Aparicio AC (2006), FEM modelling of unbonded post-tensioned segmental beams with dry joints, Engineering Structures, Vol. 28 (13), pp:1852-1863, https://doi.org/10.1016/j.engstruct.2006.03.028

[10] Turmo J, Ramos G, Aparicio AC (2012), Towards a model of dry shear keyed joints: Modelling of panel tests, Computers and $\begin{array}{lllll}\text { Concrete, } & \text { Vol. } & 10 & \text { (5), } & \text { pp:469-487, }\end{array}$ https://doi.org/10.12989/cac.2012.10.5.469

[11] Sørensen JH, Hoang LC, Olesen JF, Fischer G (2017), Test and analysis of a new ductile shear connection design for RC shear walls, Structural Concrete, Vol. 18, Issue 1, pp:189-204, https://doi.org/10.1002/suco.201600056

[12] Jørgensen HB (2014), Strength of Loop Connections between Precast Concrete Elements: Part I: U-bar Connections Loaded in Combined Tension and Bending, Part II: Wire Loop Connections Loaded in Shear. Syddansk Universitet. Det Tekniske Fakultet.

[13] Jørgensen HB, Hoang LC (2015), Load carrying capacity of keyed joints reinforced with high strength wire rope loops, Proceedings of fib Symposium 2015: Concrete - Innovation and Design.

[14] Jørgensen HB, Bryndom T, Larsen M \& Hoang LC (2016), Load carrying capacity of shear wall t-connections reinforced with high strength wire ropes. In fib Symposium 2016: Performance-based approaches for concrete structures: Proceedings.

[15] Kim HS, Chin WJ, Cho JR, Kim YJ, Yoon H (2015), An Experimental Study on the Behavior of Shear Keys According to the Curing Time of UHPC, Engineering, Vol. 7, pp:212-218, http://dx.doi.org/10.4236/eng.2015.74017

[16] Lee ChH, Chin WJ, Choi ES, Kim YJ (2011), An Experimental Study on the Joints in Ultra High Performance Precast Concrete Segmental Bridges, J. of the Korea Concrete Institute, Vol. 23 (2), pp:235 - 244, https://doi.org/10.4334/JKCI.2011.23.2.235

[17] Yang IH, Kim, KC (2012), Strength of Joint in Floating Structures Constructed with Precast Concrete Modules, Journal of Navigation and Port Research, Vol. 36, pp:197-204, http://dx.doi.org/10.5394/KINPR.2012.36.3.197

[18] Dovzhenko O, Pogrebnyi V, Yurko I (2018), Shear Failure Form Realization in concrete, News NAS RK. Series of geology and technical science, Vol. 2 (428), pp: 55-62.

[19] Dovzhenko OA, Pohribnyi VV, Karabash LV (2018) Effective Keyed Connections Of Hollow-Core Floor Slabs With Walls In Modern Large-Panel House Building, Science \& Technique, 17(2), pp:146-156, (In Russian), 10.21122/2227-1031-2018-17-2-146-156

[20] Dovzhenko O, Pogrebnyi V, Yurko I, Shostak I (2017), The bearing capacity experimental determination of the keyed joints models in the transport construction, Web of Conferences, Vol. 116 https://doi.org/10.1051/matecconf/201711602011

[21] Dovzhenko OO, Mitsnist shponkovykh ziednan betonnykh $i$ zalizobetonnykh elementiv: eksperymentalni doslidzhennia. Monohrafiia, Poltava: PoltNTU im. Yu. Kondratiuka, (2015), p:181

[22] Naotaka Y, Norimono T, Katori K, Hayashi S (1997), Study shear behavior of shear key on joints of precast concrete structure (Part 1. Summary and result of experiments), J. Struct. Constr. Eng., Architectural Institute of Japan, № 10, pp:441 - 442.

[23] Norimono T, Katori K, Hayashi S (1996), Analytical study on relations between form and shear behavior of shear key on joints of precast concrete structure, J. Struct. Constr. Eng., Architectural Institute of Japan, № 9, pp:835 - 836 . 